\title{
Ceftazidime Sodium
}

National Cancer Institute

\section{Source}

National Cancer Institute. Ceftazidime Sodium. NCI Thesaurus. Code C355.

The sodium salt of ceftazidime, a third-generation cephalosporin antibiotic with bactericidal activity. Ceftazidime binds to and inactivates penicillin-binding proteins (PBPs), enzymes located on the inner membrane of the bacterial cell wall, resulting in the weakening of the bacterial cell wall and cell lysis. Compared to the second and first generation cephalosporins, ceftazidime is more active against gram-negative bacteria and less active against gram-positive bacteria. Ceftazidine also crosses the blood-brain barrier and reaches therapeutic concentrations in the central nervous system (CNS). PBPs participate in the terminal stages of assembling the bacterial cell wall, and in reshaping the cell wall during cell division. Inactivation of PBPs interferes with the crosslinkage of peptidog lycan chains necessary for bacterial cell wall strength and rigidity. 